\title{
Engineered Gd-Co based multilayer stack to enhanced magneto-caloric effect and relative cooling power
}

Cite as: J. Appl. Phys. 123, 053902 (2018); https://doi.org/10.1063/1.5004712

Submitted: 14 September 2017 . Accepted: 17 January 2018 . Published Online: 02 February 2018

M. Tadout, C.-H. Lambert, M. S. El Hadri (D, O. Mounkachi, A. Benyoussef, M. Hamedoun, M. Benaissa, and S. Mangin (i)

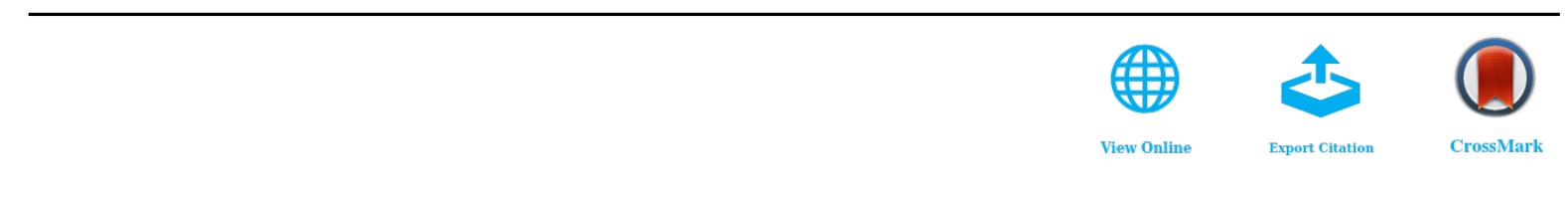

\section{ARTICLES YOU MAY BE INTERESTED IN}

Advanced materials for magnetic cooling: Fundamentals and practical aspects Applied Physics Reviews 4, 021305 (2017); https://doi.org/10.1063/1.4983612

Material-based figure of merit for caloric materials

Journal of Applied Physics 123, 034902 (2018); https://doi.org/10.1063/1.5004173

Effect of Gd substitution on the structural, magnetic, and magnetocaloric properties of $\mathrm{HoCrO}_{3}$

Journal of Applied Physics 123, 053904 (2018); https://doi.org/10.1063/1.5003637

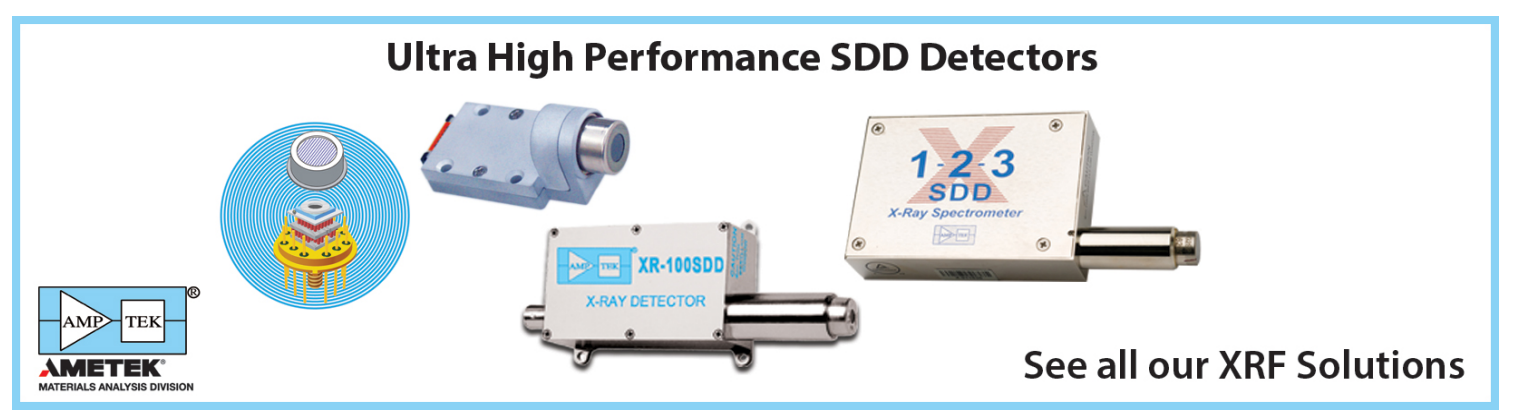

J. Appl. Phys. 123, 053902 (2018); https://doi.org/10.1063/1.5004712 


\title{
Engineered Gd-Co based multilayer stack to enhanced magneto-caloric effect and relative cooling power
}

\author{
M. Tadout, ${ }^{1,2}$ C.-H. Lambert, ${ }^{3}$ M. S. El Hadri, ${ }^{3}$ O. Mounkachi, ${ }^{2}$ A. Benyoussef, ${ }^{1,2}$ \\ M. Hamedoun, ${ }^{2}$ M. Benaissa, ${ }^{1}$ and S. Mangin ${ }^{3}$ \\ ${ }^{1}$ Laboratory of Condensed Matter and Interdisciplinary Sciences (LaMSCI), Faculty of Science, Mohammed V \\ University, B.P. 1014 Rabat, Morocco \\ ${ }^{2}$ Materials Nanomaterials Center, MAScIR Foundation, B.P. 10100, Rabat, Morocco \\ ${ }^{3}$ Institut Jean Lamour, UMR CNRS 7198, Université de Lorraine, BP 70239, F-54506 Vandoeuvre-lès-Nancy, \\ France
}

(Received 14 September 2017; accepted 17 January 2018; published online 2 February 2018)

\begin{abstract}
Magnetic refrigeration based on the magneto-caloric effect is one of the best alternatives to compete with vapor-compression technology. The viability of a magnetic refrigeration system for magnetic cooling can be tested by exploiting the materials in various forms, ranging from bulk to nanostructured materials. In order to achieve a wide refrigerating temperature range in magnetic refrigeration, we study in this paper a $100 \mathrm{~nm}$-thick Gd-Co alloys-based multilayer stack. The stack is made of four individual Gd-Co alloy layers with different values of concentration and Curie temperature $\left(T_{\mathrm{C}}\right)$. A magnetic entropy change associated with the second-order magnetic phase transition was determined from the magnetic isotherms. Moreover, the relative cooling power (RCP) of the studied Gd-Cobased multilayer is enhanced compared to the one of bulk Gd, and reaches a value of $200 \mathrm{~J} / \mathrm{kg}$. Such an enhancement of the RCP is not due to an enhanced maximum variation of entropy, but this is due to a much broader magnetic entropy peak. This study demonstrates the potential of nanostructured Gd-Co multilayer stack for magnetic cooling applications. Published by AIP Publishing. https://doi.org/10.1063/1.5004712
\end{abstract}

\section{INTRODUCTION}

Recently, magnetic refrigeration based on the magnetocaloric effect (MCE) of magnetic materials possesses the potential to substitute conventional gas compression refrigeration, and has been a topic of great interest for minimizing environmental impact. ${ }^{1}$ The basic requirement for magnetic refrigeration materials is a large isothermal magnetic entropy change $\left(-\Delta S_{\mathrm{M}}\right)$. However, several features are required for the application in magnetic refrigeration, such as the Curie temperature $\left(T_{\mathrm{C}}\right)$ in the vicinity of the working temperature, a large magnetic entropy change over the entire temperature range of range of the cycle, an almost zero magnetic hysteresis, a reasonable thermal conductivity coupled with large electrical resistance, and a large adiabatic temperature change. ${ }^{2}$ Therefore, the relative cooling power (RCP) is indeed considered to be the most important factor for assessing the usefulness of a magnetic refrigerant material. ${ }^{3}$

During the last decade, MCE has been investigated in a very wide spectrum of materials that include elemental metals ${ }^{4}$ rare earth intermetallics, ${ }^{5}$ manganese oxide materials, ${ }^{6}$ Mn alloys, ${ }^{7}$ lanthanides and Heusler compounds, ${ }^{8}$ bulk Gd alloys, ${ }^{9}$ and thin films. ${ }^{10}$ However, investigating MCE in materials at nanoscale remains a novel endeavor and an open challenge. Indeed, recent studies on $\mathrm{La}_{0.7} \mathrm{Ca}_{0.3} \mathrm{MnO}_{3}$ compounds in various forms, ranging from bulk and nanoparticles to thin films, showed that reducing the dimensionality of the LCMO compound tend to broaden and shift the paramagneticferromagnetic transition to lower temperatures, while decreasing the $M_{\mathrm{s}}$ and the magnitude of $-\Delta S_{\mathrm{M}} \cdot{ }^{11}$ Other studies on Gd-based structures demonstrated that the MCE also depends on the size and dimension. ${ }^{12,13}$ Indeed, it appears that the combination of interfaces, defects, and lower size can explain the enhancement of MCE for low dimension samples. For instance, a maximum of entropy was observed in $\mathrm{Gd} / \mathrm{W}$ multilayer. ${ }^{14}$ A more recent study by Lambert et al. showed that MCE can be tuned by changing the concentration of $100 \mathrm{~nm}$ thick Gd-Tb alloys and multilayers. ${ }^{15}$ Moreover, a recent publication has shown that the $\mathrm{Gd}_{5} \mathrm{Si}_{2.7} \mathrm{Ge}_{1.3}$ thin film exhibits a large magnetic entropy change $\left(-\Delta S_{\mathrm{M}}=8.83 \mathrm{~J} \mathrm{~kg}^{-1} \mathrm{~K}^{-1}\right.$ for $-\Delta M=50 \mathrm{kOe}$ ) and present a broader magnetic response in comparison with its bulk counterpart. ${ }^{16}$ In this paper, we report on the successful enhancement of the RCP value through the engineering of Gd-Co alloys based multilayer stack.

\section{SAMPLE STRUCTURE}

The studied sample is a $100 \mathrm{~nm}$-thick Gd-Co alloys-based multilayer stack, namely $\mathrm{Ta}(3 \mathrm{~nm}) /\left[\mathrm{Gd}_{1-\mathrm{x}} \mathrm{Co}_{\mathrm{x}} / \mathrm{Gd}_{1-\mathrm{y}} \mathrm{Co}_{\mathrm{y}} /.\right]$ $(100 \mathrm{~nm}) / \mathrm{Ta}(3 \mathrm{~nm})$. The studied sample is grown on a glass substrate at room temperature (RT) using sputtering deposition with base pressure lower than $10^{-7}$ Torr and an Ar pressure fixed at $3.0 \mathrm{mTorr}$. The composition gradients were achieved by adjusting the deposition rates from the two independent magnetron guns. Sputtering rates for $\mathrm{Gd}$ and Co targets at $50 \mathrm{~W}$ and $100 \mathrm{~W}$ were $0.719 \AA / \mathrm{s}$ and $0.456 \AA / \mathrm{s}$, respectively, as determined by low-angle X-ray reflectivity measurements. The schematic of the sample structure is illustrated in Fig. 1. Indeed, the sample is made of four $25 \mathrm{~nm}$-thick Gd-Co alloy layers, while the composition of each layer is different and varies linearly from $x=0.44$ for the first layer (bottom layer) to $x=0.60$ for the fifth layer (top layer). A $3 \mathrm{~nm}$-thick Ta buffer layer was used, whereas another $3 \mathrm{~nm}$-thick Ta capping layer was used to prevent sample oxidation. Magnetic 


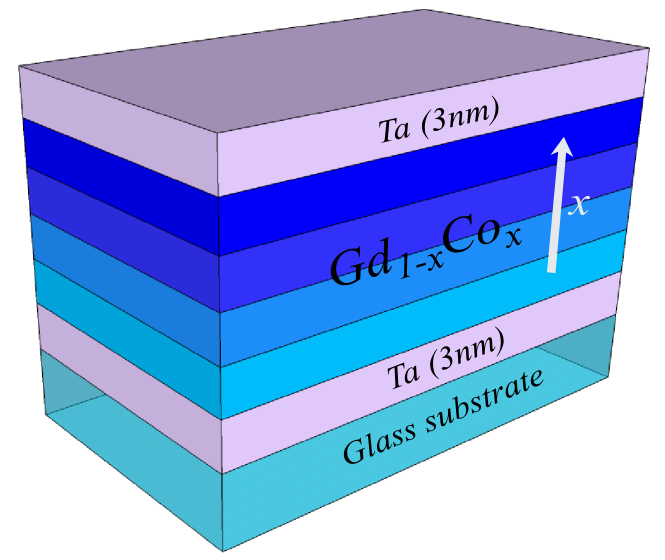

FIG. 1. Sketch of the studied Gd-Co alloys based multilayer stack. The sample is made of four $25 \mathrm{~nm}$-thick $\mathrm{Gd}_{1-x} \mathrm{Co}_{\mathrm{x}}$, where Co concentration $x$ increases linearly from 0.44 for the first layer (bottom layer) to 0.60 for the fourth layer (top layer).

measurements were carried out by a Quantum Design Squid Vibrating Sample Magnetometer.

\section{RESULTS AND DISCUSSION}

Figure 2 shows the temperature dependence of magnetization $M$ under an applied magnetic field of 500 Oe for the studied Gd-Co-based multilayer stack sample. A typical paramagnetic to ferromagnetic phase transition can be observed at $T_{\mathrm{C}}$. In order to estimate the $T_{\mathrm{C}}$, we have used the inflection point method as described by Moreno-Ramirez et al. ${ }^{17}$ Following this, a value of $T_{\mathrm{C}}=230 \mathrm{~K}$ can be determined from the minimum of the derivative of the magnetization $\frac{d M}{d T}$ as shown in the inset of Fig. 2.

The MCE in the studied Gd-Co-based multilayer stack was calculated from the isothermal magnetic entropy change $\left(-\Delta S_{\mathrm{M}}\right)$ deduced from the magnetization versus magnetic field measurements performed at different temperature below and above $T_{\mathrm{C}}$ and in magnetic fields up to $20 \mathrm{kOe}$. Figure 3 shows the temperature dependence of $M$ obtained by sweeping the magnetic field from 0 to $H_{\max }$ using a sweeping speed

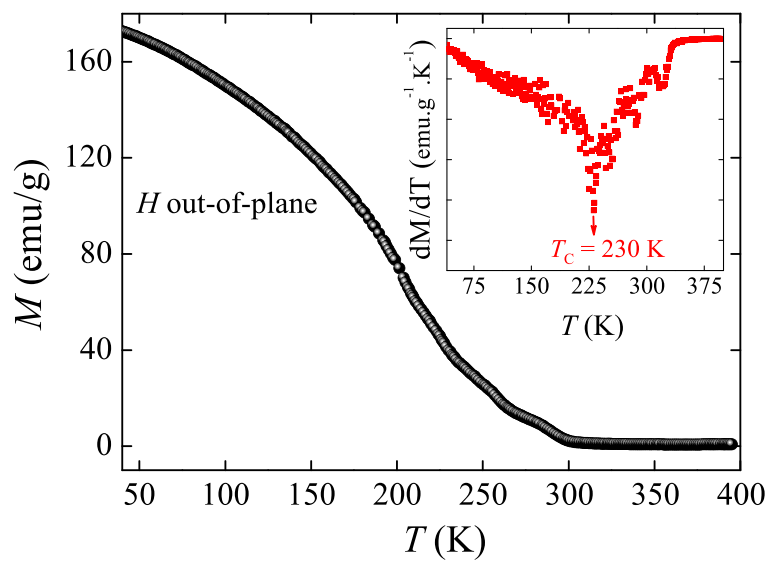

FIG. 2. Temperature dependence of the magnetization under a magnetic field of $500 \mathrm{Oe}$ for the studied Gd-Co-based multilayer stack. The inset shows the evolution of $\frac{d M}{d T}$ as a function of temperature.

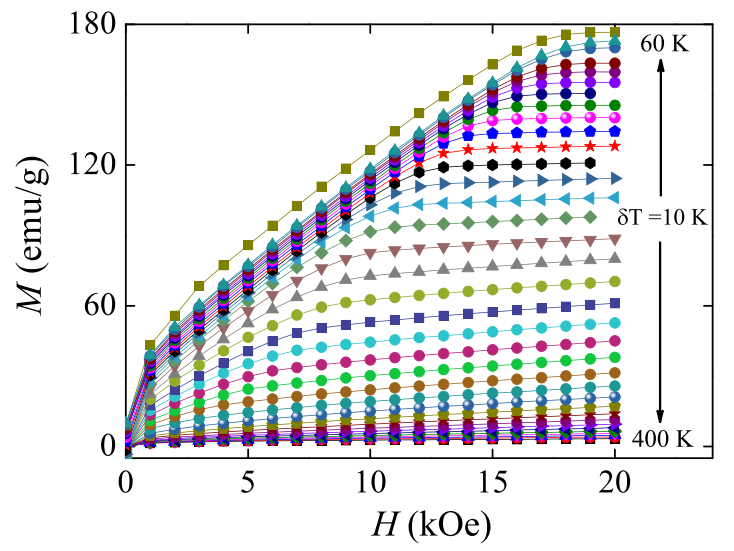

FIG. 3. Magnetic isotherms of the studied Gd-Co based multilayer studied as a function of the applied magnetic field from 0 to $20 \mathrm{kOe}$ with a sweeping rate of $250 \mathrm{Oe} / \mathrm{s}$.

of $250 \mathrm{Oe} / \mathrm{s}$, with $H_{\max }=10,15$ and $20 \mathrm{kOe}$, and for a temperature ranging from 60 to $400 \mathrm{~K}$. The isothermal magnetic entropy change $-\Delta S_{\mathrm{M}}$ is equal to $1.55 \mathrm{~J} \mathrm{~kg}^{-1} \mathrm{~K}^{-1}$ for a magnetic field swept from 0 to $20 \mathrm{kOe}$. Figure 4 shows the Arrott plots derived from $M(H)$ show a positive slops around $T_{\mathrm{C}}$. According to the Banerjee criterion, ${ }^{18}$ this finding confirms that the measured paramagnetic-ferromagnetic transition is a second-order transition.

Furthermore, we compared the values of $-\Delta S_{\mathrm{M}}$ obtained for the studied Gd-Co alloy-based multilayer stack with those obtained for a single $100 \mathrm{~nm}$-thick Gd layer and for $100 \mathrm{~nm}$ thick $\mathrm{Gd}_{1-\mathrm{x}} \mathrm{Co}_{\mathrm{x}}$ alloy layers with $x=0.44,0.48,0.52$ and 0.56 (see Fig. 5). The values of $-\Delta S_{\mathrm{M}}$ are obtained from the field dependence of the magnetization using the Maxwell relation

$$
\Delta S_{\mathrm{M}}(T, \Delta H)=\int_{0}^{H}\left(\frac{\partial M}{\partial T}\right)_{H} d H .
$$

The maximum value of $-\Delta S_{\mathrm{M}}$ is lower for the studied multilayer compared to the single Gd layer as well as the single Gd-Co alloy layers. However, the peak is much broader than for any of the single alloy layers. Note that the magnetic entropy is changed is not the only parameter to characterize the potential of a magnetic refrigerant. Indeed, the relative

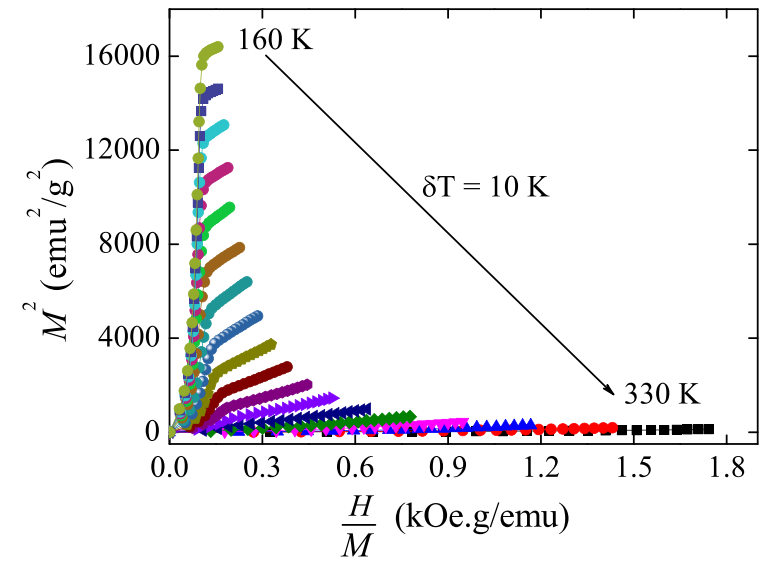

FIG. 4. Arrott plots showing the evolution of $M^{2}$ as a function of $\frac{H}{M}$ for the studied Gd-Co-based multilayer and for different values of temperature $T$. 


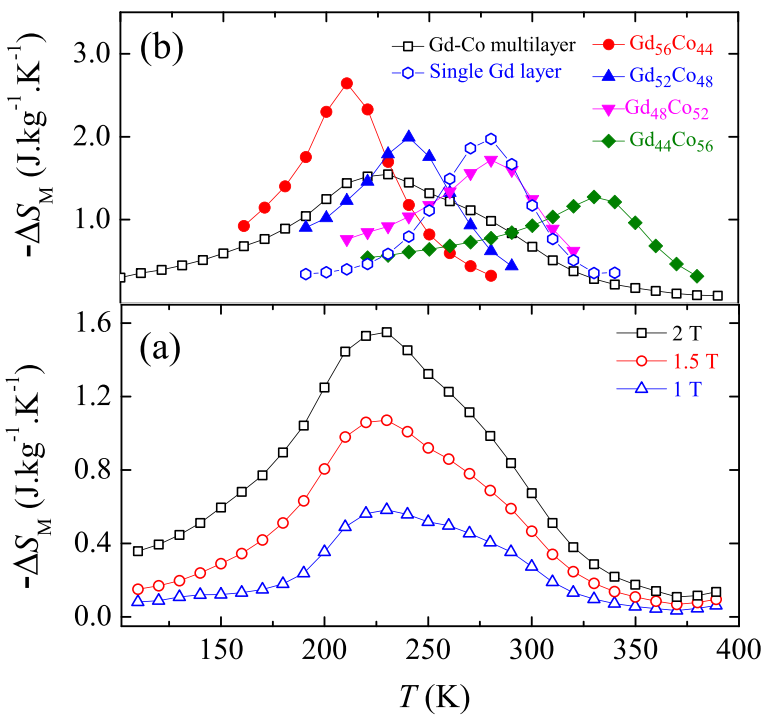

FIG. 5. Temperature dependence of the magnetic entropy change $-\Delta S_{M}$ (a) for the studied Gd-Co-based multilayer while sweeping the magnetic field from 0 to $H_{\text {Max }}$ with $H_{\text {Max }}=10 \mathrm{kOe}, 15 \mathrm{kOe}$ and $20 \mathrm{kOe}$, (b) for the studied Gd-Co multilayer, a $100 \mathrm{~nm}$-thick Gd layer, and four $100 \mathrm{~nm}$-thick $\mathrm{Gd}_{1-\mathrm{x}} \mathrm{Co}_{\mathrm{x}}$ single alloy layers with $x=0.44,0.48,0.52$ and 0.56 .

cooling power can also prove important. ${ }^{3}$ The RCP quantifies the amount of heat that can be transferred between the hot and the cold ends. For the point of view of applications, a large $\mathrm{RCP}$ over a wide temperature range coupled with a substantial MCE is desirable. The values of RCP can be calculated as

$$
R C P=-\Delta S_{\mathrm{M}}^{\max } \delta T_{\mathrm{FWHM}},
$$

with $\delta T_{\mathrm{FWHM}}$ is the full width at half maximum and $-\Delta S_{\mathrm{M}}^{\max }$ is the maximum of magnetic entropy change. ${ }^{19}$

From a technological point of view, it is important to obtain a large magnetic entropy change and a high RCP for a moderate magnetic field of $20 \mathrm{kOe}$. The measured RCP value for the Gd-Co alloys-based multilayer stack is $200 \mathrm{~J} / \mathrm{kg}$. This RCP value is slightly smaller than that reported for $\mathrm{Gd}_{5} \mathrm{Si}_{2} \mathrm{Ge}_{2},{ }^{9} \mathrm{FeRh}$ polycrystalline alloy, ${ }^{20}$ epitaxial MnAs, ${ }^{21}$ and $\mathrm{Gd}_{48} \mathrm{Co}_{52}$ amorphous ribbons ${ }^{22}$ for the same magnetic field change of $20 \mathrm{kOe}$. At the same time, the measured RCP value for the studied Gd-Co based multilayer is higher than that observed in manganite thin films, such as $\mathrm{La}_{0.67} \mathrm{Sr}_{0.33}$ $\mathrm{MnO}_{3},{ }^{23} \mathrm{La}_{0.67} \mathrm{Ba}_{0.33} \mathrm{Ti}_{0.02} \mathrm{Mn}_{0.98} \mathrm{O}_{3},{ }^{24}$ or $\mathrm{La}_{0.7} \mathrm{Sr}_{0.3} \mathrm{MnO}_{3}$ on $\mathrm{SrRuO}_{3}$ super-lattices, ${ }^{25} \mathrm{Gd} / \mathrm{W}$ multilayered films, ${ }^{26}$ and $\mathrm{Gd}_{62} \mathrm{Co}_{38}$ amorphous ribbons. ${ }^{27} \mathrm{We}$ summarize in Table I the main performances related to the MCE of the above-presented materials as well as some others reported in the literature.

\section{CONCLUSION}

In summary, we have engineered a Gd-Co-based multilayer stack sample to enhanced magneto-caloric properties. We have verified that the multilayer undergoes a secondorder transition at the Curie temperature. The value of $-\Delta S_{\mathrm{M}}$ and RCP for the studied Gd-Co alloys-based multilayer is compared to the one obtained for single Gd-Co alloy layers. The maximum $-\Delta S_{\mathrm{M}}$ for the multilayer reach $1.54 \mathrm{~J} \mathrm{~kg}^{-1} \mathrm{~K}^{-1}$ for a magnetic field change from 0 to $20 \mathrm{kOe}$ which is lower
TABLE I. Overview of the main performances related to the magnetocaloric effect for the studied Gd-Co alloys-based multilayer stack and for other materials reported from the literature. ${ }^{16,23-31}$

\begin{tabular}{|c|c|c|c|c|c|}
\hline Materials & $\begin{array}{c}-\Delta S_{\mathrm{M}} \\
\left(\mathrm{J} \mathrm{kg}^{-1} \mathrm{~K}^{-1}\right)\end{array}$ & $\begin{array}{l}\mathrm{RCP} \\
(\mathrm{J} / \mathrm{kg})\end{array}$ & $\begin{array}{l}T_{\mathrm{C}} \\
(\mathrm{K})\end{array}$ & $\begin{array}{l}\Delta H \\
(\mathrm{~T})\end{array}$ & References \\
\hline Gd/W (40 nm) & 1.41 & 52 & 275 & 1 & 26 \\
\hline $\mathrm{Gd}_{5} \mathrm{Si}_{2.7} \mathrm{Ge}_{1.3}(788 \mathrm{~nm})$ & 3.7 & 75 & 190 & 2 & 16 \\
\hline $\mathrm{Gd}(30 \mathrm{~nm})$ & 1.6 & 70 & 285 & 1 & 28 \\
\hline MnAs (70 nm) & 4 & 125 & 300 & 2 & 29 \\
\hline$[\mathrm{Gd} / \mathrm{Tb}](100 \mathrm{~nm})$ & 1.97 & 175 & 252 & 2 & 15 \\
\hline $\mathrm{La}_{0.56} \mathrm{Sr}_{0.44} \mathrm{MnO}_{3}(31 \mathrm{~nm})$ & 0.3 & 10 & 70 & 1 & 30 \\
\hline $\begin{array}{l}\mathrm{La}_{0.67} \mathrm{Ba}_{0.33} \mathrm{Ti}_{0.02} \mathrm{Mn}_{0.98} \mathrm{O}_{3} \\
(95 \mathrm{~nm})\end{array}$ & 0.99 & 49 & 286 & 1 & 24 \\
\hline Ni-Mn-Ga (400 nm) & 1.7 & $\ldots$ & 346 & 1 & 31 \\
\hline $\begin{array}{l}{\left[\mathrm{La}_{0.67} \mathrm{Sr}_{0.33} \mathrm{MnO}_{3} / \mathrm{SrTiO}_{3}\right]} \\
(20 \mathrm{~nm})\end{array}$ & 1.1 & 15 & 321 & 1 & 23 \\
\hline $\begin{array}{l}{\left[\mathrm{La}_{0.7} \mathrm{Sr}_{0.33} \mathrm{MnO}_{3} / \mathrm{SrRuO}_{3}\right]} \\
(8 \mathrm{~nm})\end{array}$ & 2.35 & 125 & 325 & 2 & 25 \\
\hline $\mathrm{Gd}_{62} \mathrm{Co}_{38}$ amorphous ribbons & 2.8 & 81.4 & 193 & 1 & 27 \\
\hline $\begin{array}{l}\left(\mathrm{Gd}_{44} \mathrm{Co}_{56}\right) /\left(\mathrm{Gd}_{48} \mathrm{Co}_{52}\right) / \\
\left(\mathrm{Gd}_{52} \mathrm{Co}_{48}\right) /\left(\mathrm{Gd}_{56} \mathrm{Co}_{44}\right)(100 \mathrm{~nm})\end{array}$ & 1.54 & 200 & 230 & 2 & This paper \\
\hline
\end{tabular}

than for any of the single Gd-Co alloy layers. However, the $-\Delta S_{\mathrm{M}}$ peak is much broader for the multilayer and the RCP value can reach $200 \mathrm{~J} / \mathrm{kg}$. Such enhancement of the RCP demonstrates the potential of Gd-Co based multilayers for magnetic refrigeration applications.

\section{ACKNOWLEDGMENTS}

We would like to thank S. Suire, C.-S. Chang, and T. Hauet for technical assistance with magnetometry measurements. This work was supported by the MESRSFC in the Framework of the national program PPR under Contract No. PPR/2015/57 and by the PHC Toubkal/17/49 project.

${ }^{1}$ K. A. Gschneidner, Jr. and V. K. Pecharsky, J. Appl. Phys. 85, 5365 (1999).

${ }^{2}$ G. L. Liu, D. A. Zhao, H. Y. Bai, W. H. Wang, and M. X. Pan, J. Phys. D: Appl. Phys. 49, 055004 (2016).

${ }^{3}$ K. A. Gschneidner, Jr., V. K. Pecharsky, and A. O. Tsokol, Rep. Prog. Phys. 68, 1479-1539 (2005).

${ }^{4}$ S. Dan'kov, A. M. Tishin, V. K. Pecharsky, and K. A. Gschneidner, Jr., Phys. Rev. B 57, 3478 (1998).

A. Y. Dong, B. G. Shen, J. Chen, J. Shen, H. W. Zhang, and J. R. Sun, J. Appl. Phys. 105, 053908 (2009).

${ }^{6}$ E. E. Bruck, O. Tegus, D. T. Cam Thanh, N. T. Trung, and K. H. J. Buschow, Int. J. Refrig. 31, 763 (2008).

${ }^{7}$ H. Wada and Y. Tanabe, Appl. Phys. Lett. 79, 3302 (2001)

${ }^{8}$ V. Franco, J. S. Blazquez, B. Ingale, and A. Conde, Annu. Rev. Mater. Res. 42, 305 (2012).

${ }^{9}$ V. K. Pecharsky and K. A. Gschneidner, Jr., Phys. Rev. Lett. 78, 4494 (1997).

${ }^{10}$ A. V. Svalov, V. O. Vas'kovskiy, A. Larranaga, and G. V. Kurlyandskaya, EPJ Web Conf. 40, 8005 (2013).

${ }^{11}$ P. Lampen, N. S. Bingham, M. H. Phan, H. Kim, M. Osofsky, A. Pique, T. L. Phan, S. C. Yu, and H. Srikanth, Appl. Phys. Lett. 102(6), 062414 (2013).

${ }^{12}$ A. V. Svalov, V. O. Vas'kovskiy, J. M. Barandiaran, K. G. Balymov, I. Orue, and G. V. Kurlyandskaya, Phys. Status Solidi A 208, 2273-2276 (2011).

${ }^{13}$ S. P. Mathew and S. N. Kaul, Appl. Phys. Lett. 98, 172505 (2011).

${ }^{14}$ B. J. Kirby, J. W. Lau, D. V. Williams, C. A. Bauer, and C. W. Miller, J. Appl. Phys. 109, 063905 (2011). 
${ }^{15}$ C. H. Lambert, M. S. El Hadri, M. Hamedoun, A. Benyoussef, O. Mounkachi, and S. Mangin, J. Magn. Magn. Mater. 433, 1-3 (2017).

${ }^{16}$ R. L. Hadimani, J. H. B. Silva, A. M. Pereira, D. L. Schlagel, T. A Lograsso, Y. Ren, X. Zhang, D. C. Jiles, and J. P. Arajo, Appl. Phys. Lett. 106, 032402 (2015).

${ }^{17}$ L. M. Moreno-Ramirez, J. S. Blazquez, V. Franco, A. Conde, M. Marsilius, V. Budinsky, and G. Herzer, IEEE Magn. Lett. 7, 6102004 (2016).

${ }^{18}$ B. K. Banerjee, Phys. Lett. 12, 16 (1964).

${ }^{19}$ M. Balli, D. Fruchart, D. Gignoux, S. Miraglia, E. K. Hlil, and P. Wolfers, J. Magn. Magn. Mater. 316, 558-561 (2007).

${ }^{20}$ M. Manekar and S. B. Roy, J. Phys. D: Appl. Phys. 41, 192004 (2008).

${ }^{21}$ D. H. Mosca, F. Vidal, and V. H. Etgens, Phys. Rev. Lett. 101, 125503 (2008).

${ }^{22}$ Z. W. Wang, P. Yu, Y. T. Cui, and L. Xia, J. Alloys Compd. 658, 598 (2016).

${ }^{23}$ V. S. Kumar, R. Chukka, Z. Chen, P. Yang, and L. Chen, AIP Adv. 3, 52127 (2013)
${ }^{24}$ M. Oumezzine, A.-C. Galca, I. Pasuk, C. Chirila, A. Leca, V. Kuncser, L. C. Tanase, A. Kumcser, C. Ghica, and M. Oumezzine, Dalton Trans. 45, 15034-15040 (2016).

${ }^{25}$ Q. Zhang, S. Thota, F. Guillou, P. Padhan, V. Hardy, A. Wahl, and W. Prellier, J. Phys.: Condens. Matter 23(5), 052201 (2011).

${ }^{26}$ C. W. Miller, D. V. Williams, N. S. Bingham, and H. Srikanth, J. Appl. Phys. 107, 09A903 (2010).

${ }^{27}$ C. L. Zhang, D. H. Wanga, Z. D. Han, H. C. Xuan, B. X. Gu, and Y. W. Du, J. Appl. Phys. 105, 013912 (2009).

${ }^{28}$ H. F. Kirby, D. D. Belyea, J. T. Willman, and C. W. Miller, J. Vac. Sci. Technol. A 31, 031506 (2013).

${ }^{29}$ D. T. Morelli, A. M. Mance, J. V. Mantese, and A. L. Micheli, J. Appl. Phys. 79, 373 (1996).

${ }^{30}$ D. D. Belyea, T. S. Santos, and C. W. Miller, J. Appl. Phys. 111, 07A935 (2012).

${ }^{31}$ V. Recarte, J. I. Perez-Landazabal, V. Sanchez-Alarcos, V. A. Chernenko, and M. Ohtsuka, Appl. Phys. Lett. 95, 141908 (2009). 